\title{
Individualidade e produção do feminino através da moda urbana Lolita
}

DOI

http://DX.DOI.ORG/10.11606/ 1678-9857.RA.2021.184475

\author{
Aline Lopes Rochedo \\ Universidade Federal do Rio Grande do Sul / Porto Alegre, RS, \\ Brasil \\ alinerochedo@gmail.com \\ ORCID: https://orcid.org/0000-0002-0622-1889
}

RESUMO

PALAVRAS-CHAVE

Este texto resulta de um exercício etnográfico realizado junto a seguidores brasileiros Individualidade, da moda urbana Lolita, estilo japonês criado na década de 1970 e inspirado no vestuário de bonecas vitorianas combinado com elementos da cultura pop nipônica. A estética se difundiu a partir dos anos 1990. Exploro a experiência de vestir Lolita e, através desta, a percepção de si e a produção de individualidades associadas à performance de gênero. Procuro demonstrar como esta indumentária específica reitera o excesso como signo do feminino, mesmo quando usada sobre corpos de homens.

Individuality and feminine production through Lolita urban fashion

ABSTRACT This article is the result of an ethnographic exercise accomplished with Brazilian followers of Lolita urban fashion, a Japanese style created in the 1970 s and inspired by Victorian doll clothing combined with rococo elements and Japanese pop culture. The aesthetics spread throughout the world from the 1990s. I explore the experience of dressing Lolita and, through it, the perception of self and the production of individualities associated with the performance of gender. I try to demonstrate how this specific outfit reiterates the excess as a sign of the feminine, even when used on men's bodies. 


\section{INTRODUÇÃO}

Este trabalho resulta de um exercício etnográfico realizado junto a adeptos brasileiros da moda urbana Lolita', estilo inspirado no vestuário de bonecas vitorianas combinado com elementos da cultura pop japonesa, em 2016². Theresa Winge (2008) e Isaac Gagné (2007) situam a criação da estética nos anos 1970, em Tóquio, como prática reativa à moda ocidental que avançava no Japão do pós-guerra. Com maior intensidade a partir da expansão da Internet, nos anos 1990, o movimento se difundiu por vários países - Brasil, inclusive - , sendo adotado, majoritariamente, por mulheres.

Exploro, a partir do ponto de vista nativo, a experiência de vestir Lolita e, por meio desta, a experimentação de si (Leitão e Comes, 2018) e a produção de sujeitos associadas à performance de gênero (Butler, 1988). Demonstro, por abordagem do tipo qualitativa, como a indumentária Lolita reitera o excesso como signo do feminino em ambientes digitais e offline. Neste processo, identifico sentidos, valores culturais e conflitos partilhados para dentro e para fora (Vencato, 2015) por pessoas cujas afinidades convergem para um determinado figurino. Minha intenção não é aprofundar a análise sobre uma moda japonesa nem sobre práticas de gênero específicas, mas me apoiar nesses elementos como chaves analíticas para acessar individualidades.

$\mathrm{Na}$ redação deste artigo, valorizei dinâmicas verificadas online, porém as considerando interligadas ao universo offline, percebendo a elaboração constante de comunicação e subjetivação (Ramos, 2015). Esforcei-me para observar jovens que constroem sociabilidades por meio de interações em ambientes relacionais na produção de identidades contemporâneas, na obtenção e na circulação de bens, imagens e conhecimento do figurino Lolita e na criação de ideias de pertencimento e coesão. Sublinho que acompanho Débora Krischke Leitão e Laura Graziela Comes quanto à necessidade de se considerar dimensões online e offline em perspectiva simétrica (2018). Inclusive, a maioria das entrevistas e da observação participante se deu em comunidades no Facebook — a rede social que eu acessava na época - ou por meio de mensagens trocadas em chats e e-mails ${ }^{3}$.

Embora na época da pesquisa eu ainda não estivesse familiarizada com a vasta literatura sobre Antropologia Digital (Miller e Horst, 2012) - e, praticamente, nem era usuária de outras mídias sociais para além do Facebook - , ficou clara a relevância da Web tanto para a composição de figurinos quanto para seus impactos nas identidades vividas, nas experiências individuais e coletivas cotidianas e nos encorajamentos e desdobramentos de ser ou vestir Lolita promovidos por contatos online de seguidores da estética. Preferi iluminar trocas de informação, artigos e suporte que se realizavam nas comunidades às quais fui admitida como membro, ao invés de me debruçar sobre tantos perfis específicos.

Observo que existem modalidades distintas de ser e vestir Lolita no tempo e no espaço. Desde os anos 1970, a estética viaja em fluxos culturais (Hannerz, 1997),
1 | Uso letra maiúscula no início da palavra Lolita quando me refiro à moda, ao movimento estético-cultural que guia este trabalho. Ao me referir às lolitas, às pessoas que adotam a moda, adoto letra minúscula no início do termo.

$\mathbf{2}$ | Este artigo é uma versão reduzida e com algumas modificações do meu trabalho de conclusão do curso do Bacharelado em Ciências Sociais (UFRCS), "'Eu me sinto no topo do mundo usando Lolita': individualidade e produção do feminino através de uma moda urbana", pesquisa realizada no segundo semestre de 2016 
adaptando-se a contextos fora do Japão. Mesmo no Brasil há especificidades, como as regionais - no Rio Crande do Sul, uma camisa Lolita importada se converte em item do traje tradicional da prenda, a "mulher gaúcha". Além disso, adeptas e adeptos entram e saem desta estética e, sujeitos urbanos que são, ingressam em outras dimensões da vida citadina.

O emprego de diferentes verbos para marcar o engajamento - vestir/usar Lolita ou ser lolita - indicará formas variadas de se relacionar com essa estética, formas que não são excludentes, mas que iluminam modos de atuar nesse panorama para alguns, trata-se de hobby; para outros, estilo de vida. Ambos os casos apontam para arranjos criativos de produção de si como ação reativa ao que consideram ser uma massificação das aparências.

Cumpre observar que movimentos jovens desencadeados nas décadas de 1960 e 1970 nos Estados Unidos, na Europa e mesmo no Japão embaralhavam fronteiras dicotômicas de vestir impostas no Ocidente no século XIX (Saulquin, 2010)4. A alteração nas relações creditadas à Revolução Industrial, à Modernidade e à consolidação do capitalismo relegou o decorativo e o adorno às vestes das mulheres. O traje masculino, associado ao público, foi distanciado de enfeites, perucas, maquiagem e bordados e direcionado ao despojamento e à discrição (Souza, 1987; Rainho 2002; Zambrini, 2010). Ou seja, a moda teve, no século XIX, papel marcante no processo de divisão e naturalização de classificação de gêneros masculino e feminino, moldando e fortalecendo uma matriz binária nas aparências (Zambrini, 2010).

Questões de gênero relacionadas ao vestuário importam na contextualização da emergência da moda Lolita nos anos 1970. Enquanto a vanguarda de estilistas desafiava as regras da então decadente alta-costura parisiense (Bourdieu e Delsaut, 2008) - e muitos designers recém-chegados ao campo apostavam em formas amplas e cores para homens e mulheres - jovens de Tóquio recuperavam elementos do século XIX e compunham figurinos de bonecas. E mais: denominavam-se lolitas, o que remetia ao livro Lolita, de Vladimir Nabokov ([1955] 2011). Veremos desconfortos e estratégias nativas para dissociar a ligação comumente feita entre pedofilia, em função da obra literária, e a moda Lolita.

Sobre estudos na paisagem urbana, e a moda é produto da metrópole, Velho (2004), inspirado em Georg Simmel (2014), chama a atenção para a cidade como um conjunto de estilos de vida, universos simbólicos, visões de mundo e sistemas de valores por onde citadinos transitam ambiguamente, colocando em tensão as culturas objetiva e subjetiva (Simmel, 2014). Entre praticantes da moda Lolita, há solidariedade, afetos e trocas, mas também há constrangimentos e conflitos latentes, principalmente no que diz respeito às regras de vestir. E há o desejo de se diferenciar, de se fazer único na multidão.

Inicio este trabalho relatando o percurso que cumpri para transformar uma curiosidade em torno de uma maneira de vestir em pesquisa sobre gênero e
4 | Entre o Renascimento e meados do século XIX, homens e mulheres se vestiam de maneira extravagante para padrões atuais. Por volta de 1830, o Ocidente recriou pela moda padrões nas formas de vestir que são excludentes - há formas para homens e para mulheres. Estas formas espelham valores opostos, deixando tecidos bordados, adereços e elementos sedutores para as mulheres: e, para os homens, a redução de elementos decorativos 
indumentária. Também recupero condições de emergência e características estéticas desse fenômeno transnacional criado nas ruas do Japão e que encontrou no meio digital potente aliado para sua expansão e para a formação de uma comunidade de sentimentos (Anderson, 2008) capaz de lhe garantir sobrevivência apesar de tantos deslocamentos globais e ressignificações locais. Encerro a primeira parte narrando minhas estratégias de inserção no campo.

Em seguida, apresento reflexões sobre o material obtido por meio de questionários publicados em comunidades no Facebook, no segundo semestre de 2016. Foram dois questionários postados num grupo do Rio Grande do Sul e um terceiro colocado num grupo de abrangência nacional. Demonstro, então, que esses jovens se aproximam do que Colin Campbell chamou de craft consumer (2005), ou seja, de um consumidor que, intencionalmente, investe tempo e capital cultural na montagem de uma composição singular. Segundo o autor, o consumo artesanal seria um oásis de autenticidade e de expressão do self (Campbell, 2005:37), uma reação à massificação da Modernidade. No caso das lolitas, justapondo peças importadas, trocadas, ressignificadas, feitas em casa e adaptadas, haveria a criação de figurinos autênticos, criativos e únicos que, embora estejam vinculados a regras definidoras do estilo, ofereceriam a sensação de expressão individual.

\section{A CENA LOLITA}

Em 2014, ouvi um apresentador de TV anunciar uma reportagem sobre uma moda urbana japonesa chamada Lolita ${ }^{5}$. A imagem na tela, no entanto, não correspondia à relação que eu fizera entre o nome do tal estilo e o erotismo sugerido no livro Lolita, de Vladimir Nabokov. A obra foi lançada em 1955, em Paris, e retrata um envolvimento sexual da pré-adolescente Dolores, ou Lolita, com o padrasto, Humbert Humbert, professor universitário de meia idade nos Estados Unidos.

Pela exibição de cenas gravadas em São Paulo, não vi imagens de adolescentes sexualmente precoces, mas de mulheres portando indumentária que me era familiar, que vira algumas vezes pelas ruas paulistanas quando morei naquela cidade. Identifiquei roupas e acessórios lembrando trajes de bonecas ou figurinos europeus do século XIX, com babados. Não relacionei a composição à moda, entendendo esta como um tipo específico de vestir associado a mudança social (Godart, 2012). À fantasia, talvez.

A matéria durou menos de três minutos. O repórter apresentou a lolita Akemi Matsuda, embaixadora kawaii 6 no Brasil, filha de japoneses. Também traduziu kawaii como fofa, falou que o Japão tem uma embaixadora kawaii para o mundo desde 2009 e dispensou longas explicações sobre a ligação com a Lolita da literatura. No quarto de Akemi, diante do guarda-roupa, parecia que a conversa sobre o vestuário fluiria, mas não. O repórter a indagou se ela andava "assim" na rua, e a entrevistada respondeu afirmativamente. E a edição passou para interações rápidas e acompanhou um

$\mathbf{5}$ |A reportagem da TV tem uma informação equivocada - Akemi não nasceu no Japão, mas no Brasil. Ela morou em Tóquio entre os 3 e os 19 anos. Disponível em https://www.youtube.com/ watch?v=T9TDfUp D9do. Acesso em 28 set 2016.

6| Expressão de difícil tradução para o português, decidi me referir a ela como "fofura", na medida em que foi a tradução que encontrei com maior frequência entre as adeptas da moda lolita no Brasil. Em inglês, kawaii é traduzido como cuteness. 
chá e um passeio das jovens de limusine. Tudo levava a crer que, uma vez trajando determinadas roupas, um conjunto de comportamentos e gostos específicos para além das vestes seria incorporado, transformando sujeitos em lolitas.

A reportagem chegou ao fim, e eu continuava não fazendo ideia sobre o que seria a tal moda Lolita. Moda por quê? Onde surgiu? Como e quando? Quem são as adeptas? Há rapazes? Por que a opção por essa estética? Quais seriam os códigos de pertencimento e de exclusão? Quem dita essa moda? Moda, fantasia ou outra coisa? Ademais, na TV, a performance me incomodava tanto quanto a maneira como o repórter interpelava as moças - mulheres com mais de 20 anos sendo tratadas como crianças e, de certa maneira, agindo como tal. E elas sorriam e batiam palmas, e tudo era caricato.

Meses depois, deparei-me com apresentações de trabalhos sobre moda Lolita em colóquios e congressos interdisciplinares. A cada exposição, aprendia algo sobre o movimento, da formação no Japão à expansão pelo mundo por meio de fluxos transnacionais que não cessam e não esgotam significados nem interpretações (Hannerz, 1997), passando por estratégias de composição dos figurinos e sociabilidade. O que na televisão parecia ser um grupo bizarro ganhava contornos de movimento urbano de jovens, no qual mulheres era a maioria. Continuava, porém, sem saber quem seriam as seguidoras da moda Lolita no Brasil, pois as apresentações ou eram pesquisas centradas, sobretudo, em São Paulo, onde há importante comunidade de descendentes japoneses, ou versavam sobre o movimento no Japão. O Rio Grande do Sul, tudo levava a crer, estava fora do circuito (Magnani, 2009).

Em 2015, porém, em Porto Alegre, cruzei numa calçada com uma moça trajando saia armada em sino, justa na cintura, camisa com babados, sapatos de bico arredondado, fitas e rendas. Devia ter por volta de 20 anos, com pele clara e cabelos longos. Perguntei-Ihe se era uma lolita, e ela respondeu que sim. E foi em frente. Voltei a refletir sobre que tipo de jovem adere a essa estética e o porquê de seguir uma visualidade de feminino produzida separadamente da moda dominante adotada no contexto urbano.

Considerando que vestes intermedeiam a percepção entre corpo e mundo, pois são objetos pessoais e acompanham os sujeitos no dia a dia, moldando-os e por eles sendo moldados, considerei as reflexões de Daniel Miller (2013), para quem a indumentária não é superficial na medida em que, "[...] em muitos aspectos, os trecos nos criam" (Miller 2013: 19). Em Trinidad, onde o antropólogo pesquisou sujeitos carentes a ponto de praticar a mendicância, mas que acumulam "de uma dúzia a vinte pares de sapatos" (Miller, 2013: 14), observou a dimensão sacra que a indumentária conquista em alguns meios sociais. $E$ isto, afirma ele, não tornaria menos profundo quem reverencia vestes.

Ademais, o autor considera a perspectiva semiótica insuficiente para pensar sobre roupas, pois faz desses objetos artigos passivos das vontades humanas. Para ele, roupas não representam pessoas nem só as vestem, mas constituem sujeitos, fazem deles o que 
são ou pensam ser (Miller, 2013). O que o intriga, portanto, são as sensações de vestir e compor figurinos e como elas interferem em noções de Eu, de pessoa e de indumentária.

Penso que questões parecidas com as de Miller poderiam ser abordadas junto a quem segue a moda Lolita. Talvez, além de indagar sobre o porquê da opção por esse estilo específico, fosse profícuo questionar acerca de quais seriam as percepções de si que emergem do ato de compor e vestir figurinos que misturam referências fabulosas. Como lolitas descreveriam a experiência de se recriar, portar e exibir esses trajes inspirados na era vitoriana combinados com elementos japoneses?

A questão se mostrou ainda mais complexa: verifiquei já nas primeiras consultas a blogs e sites que o apreço pelo estilo não é seguido só por mulheres. Brolitas ${ }^{7}$, categoria nativa para definir rapazes que se adornam com roupas e acessórios associados à indumentária Lolita, acrescentam elementos instigantes para discussões de gênero e sexualidade a esta manifestação estético-cultural que, visualmente, enfatiza noções específicas de feminilidade, mesmo em corpos de homens autodeclarados heterossexuais ${ }^{8}$ e que não se identificam com crossdressers (Vencato, 2015) nem "travestis", como diziam.

Certo é que brolitas se camuflam entre lolitas com poses, olhares, sorrisos e interações. Cobertos com vestidos, perucas e adornos, adotam, temporariamente, maneiras de agir e forjam, a partir do uso de um conjunto indumentário, novas possibilidades de constituição de gênero (Butler, 1988). Há, ainda, o boystyle, estilo composto por trajes atribuídos ao masculino, com shorts ou calças, casaco de montaria, camisa branca, botas, alguma gravata e, algumas vezes, chapéu, que cobrem corpos de mulheres ou de homens.

Suspeito, portanto, que, além de acionar elementos geracionais, como brinquedos e poses infantilizadas, praticantes de Lolita - mulheres ou homens - ou de boystyle - mulheres ou homens - embaralham e rearranjam gêneros e sexualidades na prática de estilos que, concomitantemente, reproduzem demarcações históricas de Ocidente e Modernidade quanto a diferenças entre vestir e se mover segundo convenções e expectativas para o que pertenceria aos repertórios do masculino e do feminino (Souza, 1987; Rainho, 2002). E mais: parecem lançar mão de atos criativos de expressão no consumo e na composição de seus figurinos, tornando a prática uma dentre outras manifestações estéticas que se contrapõem a noções massificadoras e dominantes nas cidades quanto a formas de vestir e se comportar, buscando um tipo de distinção por meio da adesão a uma moda alternativa.

\section{PESQUISA ONLINE E OFFLINE}

Desde a sua popularização, nos anos 1990, a Internet se cria, é criada pelos usuários e recria sujeitos em muitas possibilidades por meio de conexões globais, vinculando internautas por meio de estéticas múltiplas, ajudando a modificar hábitos de
$7 \mid$ Palavra derivada da junção do termo inglês brother (irmão) com lolita, é adotada por garotos que usam roupas femininas desta moda. É sinônimo de B-Lolita.

8| Um advogado do interior de São Paulo, com 27 anos a época da pesquisa, respondeu o questionário e me procurou inbox para contar a sua experiência, desde que eu prometesse manter sua identidade em sigilo. Insistiu em se identificar como heterossexual e confidenciou que familiares, colegas de trabalho e amigos desconhecem sua participação na cena Lolita. Havia uma costureira a quem encomendava vestidos e comprava perucas, sapatos e meias online e uma pessoa que conheceu numa comunidade do Facebook que opinava sobre os figurinos. Para além das redes sociais, ele comparecia a eventos Lolita em cidades próximas à sua, quase sempre trajando o subestilo Sweet "pela fofura". Na época da nossa conversa, estava afastado da prática a pedido da namorada. 
consumo e maneiras de viver e produzir subjetividades ao mesmo tempo em que se transforma pelos comportamentos e sentidos que provoca e inspira. No caso das lolitas, isto é evidente em redes sociais, blogs e sites. Há diferenças em cenários, poses e características físicas por questões diversas, como geográficas, étnicas, de gênero e estrato social, mas a silhueta desse estilo, pelo menos nas roupas atribuídas à noção hegemônica de feminino no Ocidente, apresenta recorrências, como saias rodadas de comprimento pelo joelho combinadas com blusas de babados e rendas.

Numa pesquisa levada com jovens urbanos imersos num fenômeno global acionado diariamente por um conjunto de ferramentas e canais digitais, é mais do que necessário reconhecer o emaranhamento dos ambientes online e offline e compreender redes sociais como espaços de experimentação de si e negociação de gênero e sexualidade elaborados pelos sujeitos e confiáveis para a produção de conhecimento etnográfico (Gomes e Leitão, 2018). Até porque, entre nascidos dos anos 1990 em diante, forjam-se laços de reciprocidade, confiança e identificação intensas com pessoas com quem convivem dentro ou fora da Web, algumas que talvez jamais encontrem fora de dispositivos eletrônicos.

Encorajada por discussões metodológicas sobre Antropologia Digital (Miller e Horst, 2012), busquei comunidades Lolita na rede social Facebook ${ }^{9}$, na expectativa de acessar aproximações e distanciamentos socioculturais, sobretudo no Brasil. Identificar marcadores de diferença poderia indicar caminho profícuo para refletir acerca de tensões e formas de se relacionar com sexualidade e distâncias econômicas e sociais, por exemplo.

Uma das comunidades na rede social é a Moda Lolita, que se apresenta como espaço para compartilhar "pequenas e rápidas informações em relação à moda Lolita", como vídeos, desfiles e reportagens com "novas coleções". No início de 2016, havia mais de 3,5 mil cadastrados de diferentes partes do Brasil e do Exterior. Pelas fotos dos perfis, a maioria era formada por mulheres brancas ${ }^{10}$, e havia rapazes e muitas imagens de personagens de animes ${ }^{11}$. Mais informações deveriam ser investigadas por outros meios, pois eu não tinha acesso à boa parte do conteúdo dos perfis para além das fotos. Foi quando considerei a possibilidade de aplicar um questionário para obter mais informações sobre os membros. Todavia, precisava ser aceita e receber autorização dos administradores para postar.

Outro grupo do Facebook que me interessou foi Lolita Sales, com mais de 10 mil participantes de diferentes regiões do Brasil na época da pesquisa. Da mesma forma que a Moda Lolita, esta comunidade mediada por brasileiras tem maioria feminina. No entanto, é um local usado exclusivamente para venda, compra e troca de acessórios e roupas. Endereços virtuais como este são essenciais na construção estética e no intercâmbio de informações desses sujeitos no país, onde não existem lojas físicas de moda Lolita, e é por meio de negociações feitas no espaço digital que se obtém uma porção de artefatos necessários para a composição dos figurinos.
9|Quando realizei a pesquisa, em 2016, não tinha aderido ao aplicativo Instagram. Revisitando o trabalho, em 2020, percorri perfis de algumas antigas interlocutoras e vi que muitas são ativas nessa rede social. Entretanto, notei que, para compra e venda de roupas e acessórios e para a troca de informação e sugestão de leituras ou de vídeos, as comunidades Lolita nas quais ingressei no Facebook parecem mais bem-sucedidas e continuam reunindo adeptas dessa estética, inclusive a "nova geração". É relevante observar, porém, que o Facebook, já na época da investigação, inclinava-se para uma espécie de envelhecimento, como Miller citou anos antes (2012), referindo-se tendência de usuários mais jovens se direcionarem a outras redes sociais.

10| Não foi possível durante a elaboração deste trabalho explorar questões de raça na medida em que não considerei confiável construir inferências a partir das imagens dos perfis de participantes das comunidades Lolita do Facebook.

11 Desenhos animados produzidos por estúdios japoneses. 
No grupo Lolita Sales, publicações de produtos à venda ou para troca que não respeitem as regras (é fundamental postar fotos, preço, medidas precisas, condições de pagamento e origem, entre outras informações exigidas) podem ser eliminadas, adverte o texto disponível a qualquer usuário da rede social. Neste caso, era provável que publicar um questionário seria inadequado, mesmo integrando o grupo. Todavia, entrando para a comunidade, eu observaria os artigos que transitam e a maneira como os intercâmbios conformam esse mercado e por ele são formados a partir de suas especificidades.

Moda Lolita e Lolita Sales são grupos fechados. Desta forma, exibem a lista de participantes e disponibilizam o conteúdo publicado apenas para integrantes admitidos pelos moderadores. Enviam-se solicitações para ingresso, e os candidatos esperam por aprovação ou rejeição. Continuei lendo sobre o assunto e investindo na busca por uma lolita em Porto Alegre que pudesse mediar a minha inserção, uma vez que não sigo a estética. A ideia era, desde o início, se aceita nas comunidades, anunciar-me como pesquisadora.

Vasculhei o Facebook em busca de alguma comunidade no Rio Grande do Sul. O Estado em geral e Porto Alegre em particular interessavam-me pelo fato de esta parte do sul não ser região de colonização japonesa. Também poderia me levar a uma lolita que me ajudasse a perceber em que medida amizades firmadas e vividas em meios digitais correspondem à construção de uma identidade de grupo também fora das redes. Por fim, encontrei conhecidas que, até então, eu ignorava serem adeptas da moda Lolita, e foram essas coincidências que me ajudaram a decifrar entrelinhas e acessar moderadores de grupos.

Desde o início do trabalho, porém, transparecia na dimensão online a ideia de coletividade construída nas redes sociais que me remetia à ideia de comunidade imaginada cunhada por Benedict Anderson (2008) ${ }^{12}$. No entanto, essa coletividade não parecia almejar a composição de identidade de grupo para além do domínio de regras, sobretudo quanto ao vestir. A sociabilidade e o envolvimento online, aparentemente, teriam maior relevância para a composição de figurinos, com compra, venda e troca, e para tornar públicos encontros entre participantes, encontros que permitiriam reuniões presenciais por algumas horas e cujos registros seriam divulgados online. Essa prática, porém, desencadeava, porém, uma série de comentários de membros da comunidade elogiando os encontros, as roupas, as iniciativas e desencadeando "convites" para amizades na rede social. Adensava-se, desta forma, a coesão na comunidade no Facebook e em outras plataformas usadas pelas integrantes, como Instagram ${ }^{13}$.

\section{LOLITAS NO PAÍS DO SOL NASCENTE}

O movimento Lolita teria se iniciado na virada dos anos 1970 para os 1980, em Harajuku, distrito comercial de Tóquio conhecido como epicentro da criação, exibição e irradiação de modas japonesas dirigidas ao público jovem (Winge, 2008). Dentre as características $\mathbf{1 2}$ | Anderson pensa comunidade imaginada a parti da ideia de nação na medida em que sua existência seria fundada em histórias, nas imagens e nas memórias associadas a elas (2008). Tomo a liberdade para usar o termo por entender que, em alguma medida, praticantes da moda transnacional Lolita se percebem como uma comunidade e enroscam suas narrativas sobre origens, práticas e visualidades.

13 Acompanhei o uso do Instagram quando a pesquisa já tinha se encerrado. Constatei que essa rede social era mais usada pelas lolitas para postagem de fotos em eventos ou em cafés, parques e praças. O mercado de artefatos Lolita se realizava mesmo no Facebook. Outra constatação posterior à finalização da pesquisa foi uma crescente produção de trabalhos acadêmicos sobre a estética e a moda Lolita anunciados nas comunidades, inclusive com postagem de questionários. 
estão outfits ${ }^{14}$ associados ao estilo de vida aristocrático europeu exibido como uma dentre tantas possibilidades estéticas cultivadas no local.

Entusiastas ocupam as ruas portando roupas com fitas, babados, saias armadas por anáguas, meias, sapatos "de boneca" ou botas, perucas, cílios postiços e sombrinhas, entre outros adornos, seguindo guidelines ${ }^{15}$ nada estáticas, muitas vezes desafiadas, adaptadas e usadas para marcar visualmente, pela composição, fronteiras entre quem é e quem não é lolita. Apesar de serem usados majoritariamente por adolescentes e pessoas na faixa dos 20 anos, esses figurinos não celebram esses grupos etários. Em outfits e trejeitos, há a exultação da fase infantil, com estampas de pirulitos, castelos e unicórnios, apenas para citar algumas, mangas bufantes, brinquedos, bonecas e bichos de pelúcia.

Guita Debert (2010), em reflexões sobre a juventude como um valor e a dissolução da vida adulta, menciona o trabalho do sociólogo inglês Frank Furedi ao falar sobre uma "crescente infantilização da cultura contemporânea" em diferentes meios, inclusive no universitário. $\mathrm{O}$ fato de um público com mais de 18 anos se interessar por desenhos, filmes, objetos, práticas e roupas produzidas para ou associadas ao mundo infantil embaça ainda mais as fronteiras entre as fases cronológicas. Debert chega a citar Hello Kitty ${ }^{16}$, uma das principais personagens do universo kawaii:

A Hello Kitty, uma gatinha branca cuja marca registrada é uma flor ou um laço vermelho, tem popularidade tremenda entre os adultos japoneses. Profissionais e funcionárias de escritórios levam material de escritório Hello Kitty para o trabalho, conversam com seus amigos em celulares Hello Kitty e usam gravatas do Snoopy (Debert, 2010: 53).

Na criação da bricolagem que constitui o repertório predeterminado e esperado da visualidade Lolita, fundamental é a presença da fofura em termos kawaii, ou seja, em termos desta estética japonesa. Evidentemente, noções de fofura variam, e há formas de vestir consideradas mais fofas do que outras em função de cores, estampas e ornamentos, com a adoção de gestos, poses e posturas padronizadas, ainda que só empregadas para registros fotográficos. Outfit que não desperta sensibilidade kawaii não é bem-sucedido.

Dos trajes, saltam fitas, rendas, tules, veludo, algodão e tricoline em composições montadas para disfarçar aspectos da silhueta adulta, como busto e quadris. Ainda assim, marca-se a cintura. O comprimento das saias deve partir da altura do joelho em direção aos tornozelos. É raro, pelo menos no Japão, ter braços, ombros, colo e costas descobertos.

A paleta de cores ajuda a definir subestilos. Quando estampadas, as roupas são floridas ou têm motivos fabulosos, com unicórnios, carrosséis, frutas, pirulitos ou corações e temáticas reconhecidas por lolitas como marcas registradas de algumas brands. Para não ser considerada ita ${ }^{17}$ - categoria nativa empregada para $\mathbf{1 4}$ | Categoria nativa para se referir ao figurino Lolita. Diz respeito à produção completa, com toda a indumentária.

15 | Categoria nativa para se referir a regras do vestir Lolita.

16| A personagem foi criada em 1974 pela empresa japonesa Sanrio. Pela biografia divulgada pela companhia Hello Kitty não é uma gata, apesar das orelhas pontudas e dos bigodes, mas uma menina inglesa. O nome Kitty, no entanto, foi retirado do livro Through the Looking Class, de Lewis Carroll, no qual um dos gatos da personagem Alice é assim nominado.

17| A palavra "ita" deriva do termo japonês itai, que significa "ai". 
desqualificar quem se pretende lolita e não se adorna conforme guidelines ou usa matéria-prima "de baixa qualidade" —, melhor evitar tecidos brilhosos. Andar com anáguas por baixo da saia é essencial.

No Japão, há rigor em relação aos cabelos, que atendem a normas de subestilos. Soltas ou presas, as mechas podem ser curtas, mas, em geral, aparecem descendo em cascatas pelos ombros, às vezes coloridas. Os fios nem sempre são longos e estão ornados com enfeites em formatos de flor, laço, morango e estrela, por exemplo, ou por chapéus.

A maquiagem é marcante, concedendo textura de porcelana à pele e escondendo manchas. Sobre os lábios, batons rosados. Já os olhos, contornados com rímel, lápis pretos e cílios postiços, recebem ênfase para parecer maiores. Como a pálpebra superior japonesa não tem a dobra comum a ocidentais, algumas recorrem a uma cola especial para uma fixação temporária da pele, formando um sulco, mas mantendo o movimento. Em alguns casos, buscam a cirurgia plástica e lentes de contato coloridas.

A fofura em objetos, poses e empenho no vestir chama a atenção desde o início da moda em Harajuku pelo investimento de tempo e dinheiro na personificação da graça e da perfeição, com jovens afirmando e reafirmando que não estavam interpretando personagens de mangás ${ }^{18}$ nem de animes. Mesmo quando se inspiram em algumas heroínas, não representariam figuras fictícias; elas seriam elas mesmas, pois ser lolita deveria ser uma maneira de viver (Winge, 2008). Razão pela qual não poderiam ser igualadas a praticantes de cosplay ${ }^{19}$, esta uma performance artística da cultura pop japonesa na qual participantes se vestem como e interpretam personagens de animes, mangás, filmes e jogos eletrônicos (Gagné, 2007). Neste hobby, imita-se um costume (fantasia) e play (jogar). Outro fictício, que até pode ser uma lolita de anime. Porém, a pessoa que veste e imita a personagem é cosplayer, não é adepta da moda Lolita. Por fim, quem é lolita e faz cosplay não pode vestir Lolita como cosplayer, ou será ita.

Sobre isto, trago um comentário da professora Sofia-interlocutora com quem me encontrei presencialmente em Porto Alegre e estabeleci contato online durante o trabalho - acerca de diferenças internas a partir do ponto de vista de quem transita em ambas as práticas. Segundo ela, fazer cosplayé encontrar uma solução criativa para chegar a um resultado esperado. Quanto à lolita, haveria muitas formas de compor um outfit, tanto no processo quanto no resultado. Cada composição seria única, ainda que a produção desse novo seja regulada por guidelines. Não posso afirmar que essa seja a lógica em Harajuku, mas é possível que esteja aí parte da aversão das japonesas à comparação com praticantes de cosplay. A pessoa lolita, nesta lógica, é a personagem de si, não a imitação do Outro, o que nos leva à crença numa autenticidade do self, na própria originalidade e potencialidade, na criatividade individual (Taylor, 2011).

O fato é que lolitas são criadas por outfits que elas criam a partir de uma matriz de regras que procura dominar as subjetividades ao mesmo tempo em que estimula 
a diferenciação (Simmel, 2014). E é principalmente pela indumentária que se reconhecem, se expressam, se aproximam e se distinguem. "É preciso saber coordenar", diz uma interlocutora, e coordenar exige capital cultural (Bourdieu, 2008), conhecimento de valores e princípios que permitem combinar conteúdo criativo e original a formas acordadas pelo campo, além de poder de compra. Ou seja, mesmo quando há criação, esta se dá dentro de um campo de possibilidades (Velho, 2004) que apregoa obediência às características pré-definidas e têm normas, constrangimentos e adaptações locais.

Esta breve incursão pela cena Lolita no Japão testemunha que roupas e poses são indissociáveis da construção da identidade desta que me sinto à vontade para chamar de moda comprometida com a reiteração do excesso como signo do feminino - pois o ornamento, o rebuscado, desde o século XIX, é atribuído às vestes usadas por mulheres. Ademais, cumpre observar que o estilo de vestir Lolita atende à lógica da indústria hegemônica e global produtora e disseminadora de modas "ocidentais". Há lojas físicas, grifes, vende-se online, editam-se revistas especializadas e catálogos, promovem-se eventos para apresentação de coleções, produzem-se editoriais e anúncios publicitários, movimenta-se dinheiro ao redor do mundo, trocam-se ideias por meio de imagens e textos, despertam-se desejos.

\section{DE LOLITA A RORIITAS}

Alguns autores associam a criação da moda Lolita a uma agência no sentido da resistência em relação ao vestir imposto pela indústria da moda Ocidental produzida em série que avançava sobre o Japão nos anos que se seguiram à II Guerra Mundial, ao sentimento de falta de individualidade pela imposição de uniformes para instituições de ensino e alguns espaços de trabalho e à supremacia da cultura patriarcal e machista (Coombes, 2016; Winge, 2008). Apesar da doçura, das fitas e dos babados, as primeiras lolitas japonesas seriam, nessa perspectiva, rebeldes num processo de transformação das subjetividades da geração do pós-guerra. Seguir essa estética fundada em padrões vitorianos, mangás e animes, fofuras nipônicas e personagens literários teria dado a esses sujeitos a sensação de subversão num contexto que insistia em lhes impor normas de vestir e agir.

Kimberley Coombes (2016) e Theresa Winge (2008) afirmam que a personagem Alice, de Lewis Carroll (1832-1898), do livro Alice no País das Maravilhas, de 1865, seria a figura mais adequada para se associar à estética dessa moda urbana. Como parte da literatura vitoriana, a obra narra os encontros de uma menina com seres fabulosos num mundo mágico e é um dos principais títulos infanto-juvenis da cultura japonesa (Coombes, 2016; Winge, 2008). O texto de Carroll também poderia ser compreendido como uma crítica à condição do indivíduo, "sufocado por inúmeras exigências e regras sociais" (Brito, s.d), e ao moralismo daquele período na Inglaterra. 
Porém, se o que define uma lolita é o outfit, as ilustrações de John Tenniel (1820-1914) para diversas edições da obra confirmam o traje de Alice como possível inspirador da estética, com saia rodada até os joelhos, meias e sapatos "de boneca".

Em suma, o outfit Lolita condensa um arranjo singular num mundo habitado por personagens da literatura e da cultura pop. Como se os figurinos fossem, em suas variações, cenários para movimentos e maneirismos infantilizados, fabulosos. E mais: locais ritualizados e alegóricos incapazes de controlar as interpretações que suscitam por onde passam, provocando emoções, tensões e inquietações que fluem de Harajuku para outros destinos habitados por adeptas e adeptos da moda até os dias de hoje.

Então, por que Lolita? Há um constante esforço de afastamento da personagem de Nabokov. Nas entrevistas que fiz com seguidoras da moda no Brasil, raras vezes houve uma menção espontânea por parte delas à Lolita da ficção. Quando eu a citava, todas reagiram no sentido de desvincular as roupas da obra literária, ainda que a explicação para a adoção da nomenclatura permanecesse desconhecida ou incerta.

Uma das explicações mais recorrentes nos trabalhos acadêmicos atesta que o nome Lolita provavelmente ingressou no ]apão via literatura, com o título traduzido para Rorita. Ee notório que o termo foi associado ao fenômeno de atração sexual de homens mais velhos por adolescentes. O complexo lolita recebeu a denominação rorikon e até inspirou um gênero de quadrinhos que objetifica mulheres (Gagné, 2008; Winge, 2008).

A razão pela qual lolitas ou roviitas adotaram a palavra para se denominar ainda não foi elucidada. Hoje, a associação entre o fenômeno japonês e o romance de Nabokov incomoda a comunidade, composta majoritariamente por mulheres, e elas se apressam para (tentar) desfazer mal-entendidos e rechaçar estereótipos ou associação a fetiche ${ }^{20}$. Uma estratégia adotada no início para afastar a "contaminação" pela conotação sexual foi modificar a grafia, acrescentando um i à palavra e criando o neologismo Roriita (Gagné, 2008; Winge, 2008). Mundo afora, porém, a moda tende a circular Lolita.

Abro parênteses para comentar a importância que teve a descoberta da denominação roriita, pois foi a partir dela que consegui localizar no Facebook a comunidade do Rio Grande do Sul, a "Roriita RS". Tratando-se de mais um grupo fechado, o conteúdo não estava disponível. Mas tive acesso à lista de membros e, dentre os 160 participantes, havia uma colega de um grupo de pesquisa acadêmica do qual participava na época, e ela me apresentou a algumas pessoas pela internet, em agosto de 2016 . Aos poucos, fui ingressando nas redes, sempre como antropóloga e pesquisadora. Jamais me fiz passar por Lolita, tampouco experimentei o vestir ou o comprar um outfit.

\section{OS QUESTIONÁRIOS}

Em setembro de 2016, fui aceita como pesquisadora na comunidade "Roriita RS", no Facebook, e as administradoras permitiram que eu postasse questionário para ser
20|Vencato (cf. 2015) explora a noção de feminilidade e o fetiche entre crossdressers. Para ser o que o campo define como crossdresser de verdade é preciso se adornar com elementos atraentes a outros homens e, ao mesmo tempo, parecer casto e assexuado. Isso permite traçar paralelos com o repúdio das lolitas à associação com a personagem da obra de Nabokov. Na estética Lolita, celebra-se a produção de um figurino "apetitoso", sweet, fofos, com morangos, pirulitos, candy colors, cerejas e cupcakes (a própria saia armada e os babados lembrando merengues), ao mesmo tempo em que se almeja o distanciamento do desejo sexual. "Como se a sexualidade fosse um botão que pode $-\mathrm{e}$ deve-ser desligado a partir do momento da montagem", provoca Vencato (2015:382). A autora também cita o trabalho de Vitor Pinheiro Grunvald (2014 apud Vencato, 2015), que constatou a mesma aversão de crossdressers ao vínculo da sexualidade. Fenômeno que se repete na cena Lolita, com as peculiaridades desse universo, habitado majoritariamente por mulheres na faixa dos 20 anos. 
respondido anonimamente. As perguntas eram: Como você conheceu a moda Lolita? Poderia fornecer sua idade, cidade onde vive, escolaridade e profissão? Se desejar, pode incluir o nickname ${ }^{21}$, mas não é obrigatório. Quando, como e por que você se tornou uma Lolita? Quando você se veste como Lolita? Quais são os comportamentos esperados de uma Lolita? Como você os aprendeu? O que é ser Lolita para você? Um estilo de vida? Uma identidade? Como se sabe quem é Lolita de verdade? O que sua família/seus amigos pensam sobre você ser uma Lolita? Com qual estilo de Lolita você mais se identifica? Por quê?

Em três dias, 10 pessoas enviaram respostas, todas indicando identidade feminina. Era um número pequeno para qualquer pesquisa quantitativa, mas satisfatório para minhas reflexões se iniciarem.

Mangás, animes, eventos de moda japonesa e internet seriam os principais canais pelos quais as colaboradoras acessaram a moda Lolita. A faixa etária se concentrou entre 21 e 25 anos. Enfatizou-se a necessidade de autonomia financeira relativa para montar outfits, considerados "caros" para a maioria das participantes. Oito vivem em Porto Alegre, uma reside em Alvorada, Região Metropolitana, e outra, em Uruguaiana, no Oeste do Estado.

Com exceção de uma estudante do Ensino Médio, e de outra que deixou o Curso Superior antes da conclusão, as demais são universitárias ou já terminaram alguma faculdade. As áreas de interesse e atividades variam. Metade da amostra está ligada a design, moda e artes, e há duas professoras, uma psicóloga e uma bióloga.

A terceira questão demonstra interesse crescente pela moda Lolita a partir de 2010, embora algumas tenham se iniciado antes. As razões para eleger o estilo evidenciam diferenças internas. Entre as justificativas, há a busca por autoestima/aceitação num grupo e expressão de feminilidade - "Me tornei lolita durante um período bem difícil da minha vida. Lolita ajudou"; "Quando eu visto roupas Lolita, me sinto também muito feminina e de bem comigo" —, pragmatismo e custo-benefício — "[...] acaba saindo mais barato do que fazer cosplay" —, noções de individualismo (Dumont, 1985; Simmel, 1973) e de cuidados e construção de si (Foucault, 1985) — "[...] estilo que combinava comigo, com o que eu imaginava e com como eu queria ser"; "[...] a estética tem a ver com a maneira que eu sempre me vesti"; "[...] é algo singular". Uma das respostas desafiou a questão: “[...] pessoas não 'são' lolitas, roupas são: lolita é o estilo de moda, não as pessoas". Segundo esta participante, "pessoas usam/vestem Lolita".

Enquanto algumas respostas são dispersas, a pergunta sobre o que esperar em termos de comportamento Lolita apontou para a negação da existência de padronização, contrastando com informações da internet. Ao ler o questionário, aliás, uma participante me alertou inbox para a probabilidade de as respostas não corresponderem às minhas "expectativas". "Somos nós mesmas, não interpretamos algum tipo de papel, como cosplayers fazem"; "[...] como se a personalidade de uma pessoa fosse 
mudar em função da roupa que ela veste..."; "Não me comporto de maneira diferente da minha original personalidade."

Para a maioria, a moda não afeta/modifica suas "maneiras de ser". Ao mesmo tempo, algumas, em situações presenciais comigo, relataram alterações na forma como se percebem ao se adornarem com o outfit. Uma testemunhou que, trajando camiseta, jeans e tênis, é "mais tímida". Usando Lolita, assegura, consegue erguer a cabeça, caminhando altiva e se sentindo fofa. Outra disse que, com o outfit, sente-se uma versão melhorada de si. Como se o traje tornasse manifesto o self, evidenciasse algo que estaria escondido dos outros.

Desta forma, a interioridade é entendida como descolada das subjetividades, ainda que tenha modificado hábitos de consumo, redes de relações e práticas de vestir. Neste sentido, Taylor (2011) diz que a ideia de cada indivíduo como sendo diferente e original é uma noção dominante no Ocidente moderno e que, mesmo podendo se espalhar pelo mundo, é estranha em outras culturas e em outros tempos.

Também chamou a atenção a recorrência do termo "respeito" nas respostas, apontando para uma solidariedade desejada a ser cultivada e praticada entre lolitas em relação a gostos, produções dos outfits e em diferenças de gênero - quando homens ou mulheres vestem as roupas atribuídas aos seus gêneros convencionados como opostos, com homens usando Lolita e mulheres trajando boystyle. Não deixa de ser um indicador de que conflitos de classe e gênero são latentes internamente. Já os significados de ser lolita são múltiplos em função das vivências e expectativas diversas das pessoas das comunidades, comunidades feitas e refeitas por sujeitos urbanos, modernos e fragmentados (Velho, 2004). Lolitas não podem ser pensadas, desta forma, como integrantes de uma totalidade.

Identidade, estilo de vida, liberdade, modo fofo de vestir, hobby e extensão do ser e forma de expressão foram expressões usadas nas respostas. Para a maioria das colaboradoras do Rio Grande do Sul, ser "lolita de verdade" implica adotar silhueta a partir de regras básicas, a saber, uso de saia de armação, qualidade de materiais, sem decote, a saia levemente acima do joelho, blusa de rendas. É importante dominar as guidelines. O maior ou menor domínio das regras do campo (Bourdieu, 2008) diferencia "novatas" de "veteranas".

Outfits são montados em esplendor para meetings e eventos de cultura japonesa em espaços públicos ou para o registro imagético seguido de publicação em algum canal online. Existe uma estética singular que reconfigura fronteiras políticas e geográficas e se expressa em habilidades manuais e domínio de linguagem e conhecimento sendo ressignificada, perpassando parques, ruas, shoppings, sites, revistas e filmes, conectando lugares, pessoas, ideias, tecnologia, capital, imagens e informação (Appadurai, 1999).

Chamou-me a atenção que, mesmo com anúncios publicitários empregando modelos esguias, a silhueta exaltada é aquela formada pela composição de blouse e 
saia rodada "até o joelho" - pode ser uma explicação para o porquê de brolitas se sentirem tão à vontade com roupas Lolita. Em suma, o contorno do outfit e o cumprimento de guidelines parecem mais relevantes do que formas e dimensões corporais para que se atinja o resultado almejado.

Por fim, sete das dez pessoas participantes admitiram resistência ao outfit por parte de familiares e pessoas próximas, às vezes pelo dispêndio de dinheiro, outras vezes pela acusação de infantilidade. Em geral, essa relação é narrada com início conflituoso, mas se encaminha para aceitação e apoio, inclusive na escolha das roupas. Na relação para fora da cena, mães seriam as principais entusiastas - num dos casos é a avó - e amigos tendem a ser solidários. Com os homens - pais, principalmente -, a tensão retumba no silêncio.

A partir das respostas acima, elaborei um segundo questionário para a comunidade "Roriita RS", incluindo questões sobre condições socioeconômicas. E arrisquei um terceiro formulário direcionado para fora do Estado, postando-o na comunidade Moda Lolita. Este último não era idêntico ao segundo nem ao primeiro, mas era uma mistura de ambos.

Meu objetivo com os instrumentos de pesquisa era procurar recorrências, identificar e compreender regras, apropriar-me do léxico e perceber semelhanças e diferenças internas. Houve 11 participantes no segundo questionário do "Roriita RS" e 30 no formulário que postei na Moda Lolita. Nesta segunda fase, portanto, somei 41 colaboradores, 36 identificados com feminino; três, com masculino, todos brolitas; $\mathrm{e}$ dois, com "outros", mas usando "o" no final dos adjetivos, indicando preferência pela identificação com o gênero masculino.

A concentração de idade, no Brasil e no Rio Grande do Sul, correspondeu à faixa de 21 a 24 anos. Pelo menos dois terços residem com a família, cursa ou cursou alguma faculdade ou pós-graduação e usa transporte público como principal meio de locomoção. A maioria estuda e trabalha, e as principais áreas de interesse estão ligadas às artes, à moda, ao design, à beleza e à História. Há concentração nas capitais, embora a cena avance para o interior.

Uma pergunta que consta do formulário que circulou no "Roriita RS" e foi suprimida daquele enviado à Moda Lolita indaga sobre bairro de residência. Com base nas respostas, afirmo que, no caso de Porto Alegre, há quem siga a estética tanto em zonas populares e periféricas quanto em regiões nobres e centrais. $\mathrm{Ou}$ seja, sujeitos de diferentes camadas sociais se encontram na cena e compartilham o interesse por esta manifestação estético-cultural. Se essas mesmas pessoas mantêm relações face a face para além dos encontros de cultura japonesa e dos meetings, era algo a investigar.

Incluí no formulário para o grupo Moda Lolita a pergunta sobre quando, como e por que tornar-se entusiasta da modalidade. O interesse da maioria se iniciou entre 12 e 15 anos, por meio de mangás, animes, Internet e eventos de cultura japonesa, mas 
conseguir compor o outfit não era possível em função do alto custo - trabalhar e ganhar dinheiro facilita a adesão.

Tanto no Estado como no restante do país, a maioria identifica a prática como hobby, atividade à qual se dedica tempo, esforço e recursos em busca de algum tipo de prazer e satisfação quando outfits são contemplados e exibidos. É roupa para "ocasiões especiais", como aniversários, festas e passeios. Não é, portanto, vestimenta cotidiana, a não ser em detalhes e na composição do subestilo que se chama casual lolita: saia rodada, alguns acessórios, bolsa, os sapatos etc. combinados com roupas usadas pela maioria dos habitantes das cidades. Acessórios, como colares e anéis, porém, acabam incorporados ao cotidiano.

Também convergem para o outfit ideias de criação e expressão de algo pensado como interior aos sujeitos, como essenciais do indivíduo (Dumont, 1985) dotado de criatividade, emoção e imaginação que visa o prazer (Campbell, 2001), e noções de "autodescoberta" e moralidade: "[...] percebi que havia um grupo de garotas que transformava em realidade tudo aquilo que eu amava e via apenas em livros e filmes"; "[...] é uma moda ao contrário da exploração da forma do corpo no sentido sexual"; "[...] era tudo o que eu procurava"; [...] não me apaixonei apenas pelos vestidos, mas pela atitude das meninas e dos meninos"; "[...] estilo lindo, delicado e diferente. Eu me sinto no topo do mundo usando lolita"; "[...] me sinto linda"; "Remete ao passado, à inocência, ao que deveríamos ser no futuro"; "[...] detalhes, recato, camadas"; "permite que a gente mostre a nossa personalidade".

Cumpre sublinhar relatos sobre conflitos entre familiares e amigos. Há apoio, mas há constrangimentos e ressentimentos: "[...] consideram-me corajosa e estranha por usar roupas 'de criança"; "[...] alguns ficam preocupados com minha segurança"; "[...] há muito desrespeito, desde comentários, piadas até fotos sem permissão"; [...] dizem que essas roupas não são apropriadas para sair"; "[...] ninguém pagava minhas roupas, não tinha por que reclamar de nada"; "Acham que é só uma fase".

Sobre tantas estratégias para compor figurinos, sabemos que a maior parte das lojas Lolita é japonesa, e são altas as taxas cobradas pelas remessas e pela importação. "Vestidos de marcas japonesas custam, facilmente, 700 ou 800 reais. Meus vestidos e saias são handmade e réplicas de marcas japonesas. Os vestidos valem 150 reais, e as saias, 70 reais", respondeu uma das lolitas do Rio Grande do Sul.

Participantes reconhecem que importam menos nos últimos anos por causa da cotação do dólar. Algumas investiram em máquinas de costura para produzir saias, vestidos e blusas. Outras fazem adereços para si e para vender. Duas lojas no Brasil se especializaram em sapatos. Costureiras também são contratadas para a produção, especialmente por brolitas e lolitas plus size ${ }^{22}$, em geral porque as silhuetas não acompanham as curvas das roupas prontas ou mais ofertadas em sites ou comunidades de compra, venda ou troca.

$22 \mid$ Plus size significa

"tamanho grande" e é uma categoria nativa no campo da moda usada para designar pessoas gordas e tamanhos de roupas para numerações acima de 44 ou 46 , não há consenso. Pode-se ser plus size e/ou vestir plus size. 


\section{CONSIDERAÇÕES FINAIS}

Explorei uma composição indumentária como elemento constitutivo da construção de indivíduo numa performance de gênero. Parti da moda Lolita para demonstrar como se produz a feminilidade das adeptas deste movimento estético-cultural criado no Japão da década de 1970 e que se consolidou em contextos urbanos brasileiros na esteira do avanço da Internet, na virada dos anos 1990 para os 2000.

Seguindo abordagem do tipo qualitativa, compus uma narrativa com base em respostas obtidas por meio de questionários que publiquei em comunidades no Facebook; em entrevistas e encontros em Porto Alegre; em conversas informais; na observação participante junto a grupos online; em catálogos de brands; em consulta a blogs, sites e trabalhos acadêmicos sobre lolitas; na literatura; e em análises de imagens - fotografias e anúncios publicitários - objetos e performances de sujeitos que circulam neste campo.

Situei meu interesse inicial pela moda Lolita, em 2014, como curiosidade. Foi após me deparar com uma moça trajando esse estilo em Porto Alegre, no final de 2015, que olhei para o fenômeno como potencial objeto de pesquisa antropológica com jovens urbanos. Assim, estabeleci contatos no Rio Grande do Sul e me aproximei do tema por meio de sites, blogs e trabalhos acadêmicos. A pesquisa se intensificou quando obtive autorização para publicar questionários no Facebook — as comunidades Lolita são fechadas e, em algumas, não são permitidas postagens como formulários - e negociei entrevistas.

No meio digital, onde se produzem singularidades e diferenças (Miller e Horst, 2012), verifiquei como lolitas e brolitas constroem e alimentam redes de sociabilidade e trocam informações e coisas, embaralhando fronteiras culturais, sociais, de gênero, geracionais e políticas, compondo uma comunidade de sentidos (Anderson, 2008). Vendem, negociam, compram, revendem, promovem leilões. Também se apoiam, percebem-se coesos, compartilham, criam laços e ampliam o conhecimento sobre o que os une, experimentando-se a si mesmos (Comes e Leitão, 2018).

Em reuniões presenciais ou em plataformas digitais, esses jovens são quem quiserem ser. Nos meetings ou em eventos de cultura japonesa, o julgamento não se dá por posição social. Importa é saber coordenar, dominar regras para se adornar em sonhos e fábulas, acumular capital cultural (Bourdieu, 2008) que lhes permita celebrar individualidades pelo reconhecimento de uma estética e por valores culturais para atingir visualidades capazes de sintetizar princípios do grupo.

Lolitas e brolitas compram, descartam, fabricam e rearranjam objetos na construção dos outfits e de si mesmos. É uma construção estética numa temporalidade diferente daquela do cotidiano dos centros urbanos. Criar um figurino leva dias, semanas, meses e até anos. Mais do que se opor à moda hegemônica, o objetivo é a construção da individualidade a partir de um estilo baseado em o quê se porta e em 
como se portam roupas e acessórios, o que nos permite evocar Campbell e sua noção de craft consumer (2005). Mesmo usando peças de segunda mão ou massificadas, orgulham-se de recombiná-las dentro das regras. Copiar personagens é cosplay, é se passar por um Outro fictício. Para quem usa - ou veste - Lolita, seria coisa de ita. Há, portanto, conflitos latentes, pois quem não respeita as regras do outfit e de postagem nas comunidades em ambientes digitais pode sofrer sanções e intimidações. Daí a insistência no respeito às diferenças, pelo menos em público.

$\mathrm{O}$ apreço pela moda Lolita destoa da moda dominante pensada dicotomicamente, pois essa adesão embaralha fronteiras de masculino e feminino e reconfigura limites geracionais, geográficos, históricos, públicos e privados. Podem-se disfarçar curvas, silhueta adulta, busto, quadris, feições online e offline. Isto facilita, por exemplo, a participação de brolitas na cena, na medida em que são as anáguas que dão forma aos contornos corporais importantes.

Para as mulheres, uma das maiores barreiras de aderir ao estilo está na dissociação entre a moda e a origem do nome, ao que parece ter sido extraído do livro Lolita, de Nabokov, de 1955. Lolitas se esmeram em encontrar explicações e desvios para se distanciar de associações de cunho sexual.

Pensar com lolitas e brolitas ilumina reflexões antropológicas na medida em que o movimento mistura um estilo de vestir outrora elegante no Ocidente, o reelabora, acrescenta o kawaii, exporta essa forma a vários países e permite a experimentação de si. Adeptas e adeptos modificam a prática localmente, refutam algumas regras, aproximam-se de guidelines, abrem caminho para se pensar construções de gênero, individualidade e subjetividades. Além disso, possibilita novos arranjos num vaivém de significados e interpretações que não cessam e sobre os quais os sujeitos da cena não têm controle.

Aline Lopes Rochedo é Doutora em Antropologia Social (UFRCS), mestra em Antropologia Social (UFRCS) e bacharela em Ciências Sociais (UFRGS) e Comunicação Social/Jornalismo (PUCRS). Tem interesse nas áreas de Antropologia Econômica, Antropologia dos Objetos e Antropologia Visual.

FINANCIAMENTO: Não se aplica

CONTRIBUIÇÃO DE AUTORIA: Não se aplica 


\section{REFERENCIAS BIBLIOCRÁFICAS}

ANDERSON, Benedict. [1983] 2008.

Comunidades imaginadas: reflexões sobre

a origem e a difusão do nacionalismo.

São Paulo, Companhia das Letras.

APPADURAI, Arjun. [1994] 1999. “Disjunção e diferença na economia cultural global". In FEATHERSTONE, Mike (org.). Cultura global. Petrópolis, Editora Vozes, pp. 311-328.

BOURDIEU, Pierre. [1979] 2008. A distinção: crítica social do julgamento. Porto Alegre, RS, Zouk.

BOURDIEU, Pierre e DELSAUT, Yvette. [1975] 2008. "O costureiro e sua grife: contribuição para uma teoria da magia". In BOURDIEU, Pierre. A produção da crença: contribuição para uma economia dos bens simbólicos. Porto Alegre, RS, Zouk, pp. 113-190.

BRITO, Bruna Perrella. "Alice no País das Maravilhas: uma crítica à Inglaterra vitoriana". Centro de Comunicação e Letras, Universidade Presbiteriana Mackenzie, São Paulo. Disponível em: http://www. mackenzie.br/fileadmin/Graduacao/CCL/ projeto_todasasletras/inicie/BrunaBrito. pdf. Acesso em 7 de setembro de 2016.

BUTLER. Judith. 1988. "Performative acts and gender constitution: an essay in phenomenology and feminist theory". Theatre Journal n. 40: 519-531. Disponível em: http://www.jstor.org/stable/3207893. Acesso em 6 de agosto de 2009.

CAMPBELL, Colin. [1987] 2001. A ética romântica e o espírito do consumismo moderno. Rio de Janeiro, Rocco.

CAMPBELL, Colin. 2005. "The craft consumer: culture, craft and consumption in a postmodern society". Journal of Consumption Culture n. 5: 23-42.

COOMBES, Kimberlee. 2016. Consuming Hello Kitty: saccharide cuteness in Japanese society. Boston, Dissertação de mestrado, Wellesley College. Disponível em: repository.wellesley.edu/cgi/viewcontent. cgi?article $=1527 \&$ context=thesiscollection . Acesso em 20 de junho de 2016.

DEBERT, Guita Grin. 2010. "A dissolução da vida adulta e a juventude como valor". Horizontes Antropológicos (34), jul./dez.: 49-70.

DUMONT, Louis. 1985 O individualismo: uma perspectiva antropológica da ideologia moderna. Rio de Janeiro, Rocco.

FOUCAULT, Michel. [1984] 1985. A história da sexualidade: o cuidado de si. Rio de Janeiro, Graal.

GACNÉ, Isaac. 2008. "Urban Princesses: performance and women's language in Japan's Gothic/Lolita subculture". Journal of Linguistic Anthropology n. 18: 130-150.

GODART, Frédéric. 2012. Sociología de la moda. Buenos Aires, Edhasa.

GOMES, Laura Graziela e LEITÃO, Débora Krischke. 2018. "Gênero, sexualidade e experimentação de si em plataformas digitais on-line". Civitas, Porto Alegre, v. 18, n. 1, jan./abr.: 171-186.

HANNERZ, Ulf. 1997. "Fluxos, fronteiras, híbridos: palavras-chave da antropologia transnacional". Mana, Rio de Janeiro: 7-39. Disponível em: http://www.scielo.br/ scielo.php?script=sci_arttext\&pid=S010493131997000100001\&lng=en\&nrm =iso. Acesso em 27 out. 2016. 
MAGNANI, José Guilherme Cantor. 2009. "Etnografia como prática e experiência”. Horizontes Antropológicos, v. 32, jul./dez.: 129-156.

MELLO E SOUZA, Gilda de. 1987. O espírito das roupas: a moda do século dezenove. São Paulo, Companhia das Letras.

MILLER, Daniel. [2010] 2013. "Por que a indumentária não é algo superficial”. In: MILLER, Daniel. Trecos, troços e coisas: estudos antropológicos sobre a cultura material. Rio de Janeiro, Zahar, pp. 21-65.

MILLER, Daniel. 2012. "Social networking sites”. In: MILLER, Daniel e HORST, Heather, A. (org.), Digital anthropology. Londres, Nova York, Berg, pp. 146-161.

MILLER, Daniel e HORST, Heather A. 2012. "The digital and the human: a prospectus for digital anthropology". In MILLER, Daniel e HORST, Heather, A. (org.), Digital anthropology. Londres, Nova York, Berg, pp. 3-35.

NABOKOV, Vladimir. [1955] 2011. Lolita. Rio de Janeiro, Objetiva.

RAINHO, Maria do Carmo Teixeira. 2002. A cidade e a moda. Brasília,

Editora Universidade de Brasília.

RAMOS, Jair de Souza. 2015.

"Subjetivação e poder no ciberespaço.

Da experimentação à convergência identitária na era das redes sociais". Vivência: Revista de Antropologia, n. 45: 57-76.
SAULQUIN, Susana. 2010. La muerte de la moda, el día después. Buenos Aires, Paidós.

SIMMEL, Georg. [1900] 2014. "A divisão do trabalho como causa da diferenciação da cultura subjetiva e objetiva". In: SOUZA, Jessé; ÖELZE, Berthold (org.). Simmel e a modernidade. Brasília, Editora Universidade de Brasília, pp. 41-76.

SIMMEL, Georg. [1902] 1973. A metrópole e a vida mental. In: VELHO, Otávio Guilherme. O fenômeno urbano. Rio de Janeiro, Zahar Editores, pp. 11-25.

TAYLOR, Charles. 2001. Sources of the self: the making of the modern identity. Cambridge, Massachusetts, Harvard University Press.

TAYLOR, Charles. 2011. A ética da autenticidade. São Paulo, Realizações.

VELHO, Gilberto. [1987] 2004. Individualismoe cultura: notas para uma antropologia da sociedade contemporânea. Rio de Janeiro, Jorge Zahar Ed.

VENCATO, Anna Paula. 2015. "Entre 'reais' e 'virtuais': noções sobre risco e verdade em um clube brasileiro de crossdressers". Cadernos Pagu, n. 44: 367-390.

WINGE, Theresa. 2008. "Undressing and Dressing Loli: a search for the identity of the Japanese Lolita". Mechademia (3), Minnesota, University of Minnesota Press, pp. 47-63.

ZAMBRINI, Laura. 2010. "Modos de vestir e identidades de género: reflexiones sobre las marcas culturales en el cuerpo". Revista de Estudios de Cénero Normadías, n. 11: 130-149.

Recebido em 20 de dezembro de 2018. Aceito em 29 de julho de 2020. 